\title{
IMPACTOS AMBIENTAIS E SERVIÇOS ECOSSISTÊMICOS EM ÁREAS DE MANGUEZAL
}

\author{
Elza Edimara Soares da Silva ${ }^{(a)}$, Lutiane Queiroz de Almeida ${ }^{(b)}$ Yuri Marques Macedo ${ }^{(c)}$ \\ (a) GEORISCO/DGE/CCHLA/UFRN. edimarageo@live.com> \\ (b) GEORISCO/PPGE/CCHLA/UFRN. lutianealmeida @ hotmail.com \\ (c) GEORISCO/DGE/CCHLA/UFRN. yurimmacedo@ hotmail.com>
}

Eixo: Uso e ocupação das terras e legislação ambiental

\begin{abstract}
Resumo
O bem-estar social relaciona-se com diversas variáveis, tais como, saúde, emprego, moradia, qualidade de vida e salário. A inclusão dos serviços ecossistêmicos como uma dessas variáveis, além de se configurar como uma importante ferramenta para os estudos relacionados ao meio ambiente trouxe a discussão sobre os benefícios os quais um ecossistema pode prover à sociedade. A partir disso, verificou-se que o ecossistema de manguezal, pelo fato de se tratar de um ecossistema costeiro de transição e ser responsável por diversas funções importantes para a fauna marinha e estuarina, configura-se como um importante ambiente a ser estudado, a partir da análise de seus serviços ecossistêmicos. Dessa forma, identificaram-se os impactos ambientais sobre os serviços ecossistêmicos, no manguezal presente no estuário do rio Potengi, em Natal/RN - Brasil, a partir da análise em campo, na área de estudos, o que configurou uma importante etapa para fomentar medidas de proteção a este importante ecossistema.
\end{abstract}

Palavras chave: Serviços ecossistêmicos. manguezal. impactos ambientais.

\section{Introdução}

O manguezal trata-se de um ecossistema costeiro de transição entre os ambientes terrestre e marinho, característico das zonas tropicais e subtropicais; é um ambiente bastante dinâmico, o qual é facilmente influenciável pelo regime das marés, visto que sua área predomina em regiões baixas e planas, como estuários, margens de lagunas, bem como ao longo de rios ou canais naturais (SCHAEFFER-NOVELLI). Trata-se de um ecossistema de grande importância socioambiental, já que diversas espécies marinhas o utilizam como berçário para a sua reprodução, assim como marisqueiros, pescadores e catadores de caranguejo e moluscos, utilizam estas áreas para garantir seus sustentos.

Na cidade de Natal (Rio Grande do Norte) as áreas de manguezal encontram-se presentes no estuário do rio Potengi, estendendo-se ao longo de suas margens. Para fins de preservação e conservação de áreas onde as características do meio físico necessitam de ordenamento no tocante ao uso e ocupação do solo, o Plano Diretor de Desenvolvimento Urbano (PDDU), estabeleceu a criação de dez Zonas de Proteção Ambiental (ZPA's) ao longo de todo o município (Lei $\mathrm{N}^{\circ} 4.664$ de 31 de julho de 1995). A ZPA 
correspondente aos manguezais do estuário do Rio Potengi, é a ZPA 8, ou Zona de Proteção Ambiental do Ecossistema Manguezal e Estuário do Potengi/Jundiaí (NATAL, 2007).

Dessa forma, o objetivo deste artigo é elencar os principais impactos ambientais atuantes sobre os serviços ecossistêmicos e suas consequências sobre estes serviços. Realizou-se uma visita técnica na área de estudos, procedimento indispensável para o reconhecimento da área, bem como para a identificação dos impactos ambientais e serviços ecossistêmicos existentes.

Por serviços ecossistêmicos, entende-se como benefícios relevantes para a sociedade, gerados pelos ecossistemas. De acordo MEA (2005), entende-se por serviços ecossistêmicos, os benefícios obtidos pelas pessoas a partir dos ecossistemas. Já para De Groot et al. (2002), os serviços ecossistêmicos referem-se à capacidade dos processos ou funções que os ecossistemas e seus componentes possuem, de fornecer produtos e serviços que possam atender as necessidades humanas, de forma direta ou indireta. Estes serviços estão divididos em quatro categorias, sendo elas: suporte, culturais, provisão e regulação.

\section{Procedimentos metodológicos}

Para a realização desta pesquisa optou-se por trabalhar com a Zona de Proteção Ambiental 8 (ZPA 8) de Natal. Localizada nas regiões administrativas norte e leste da cidade, também é conhecida por Zona de Proteção Ambiental do Ecossistema Manguezal e Estuário do Potengi/Jundiaí (NATAL, op.cit.). Esta zona de proteção foi estabelecida no Plano Diretor de 1994 (NATAL, 1994) e teve sua delimitação estabelecida por coordenadas geográficas na atualização do Plano, em 2007 (Natal, 2007, art. 18, h e Anexos II e III). 


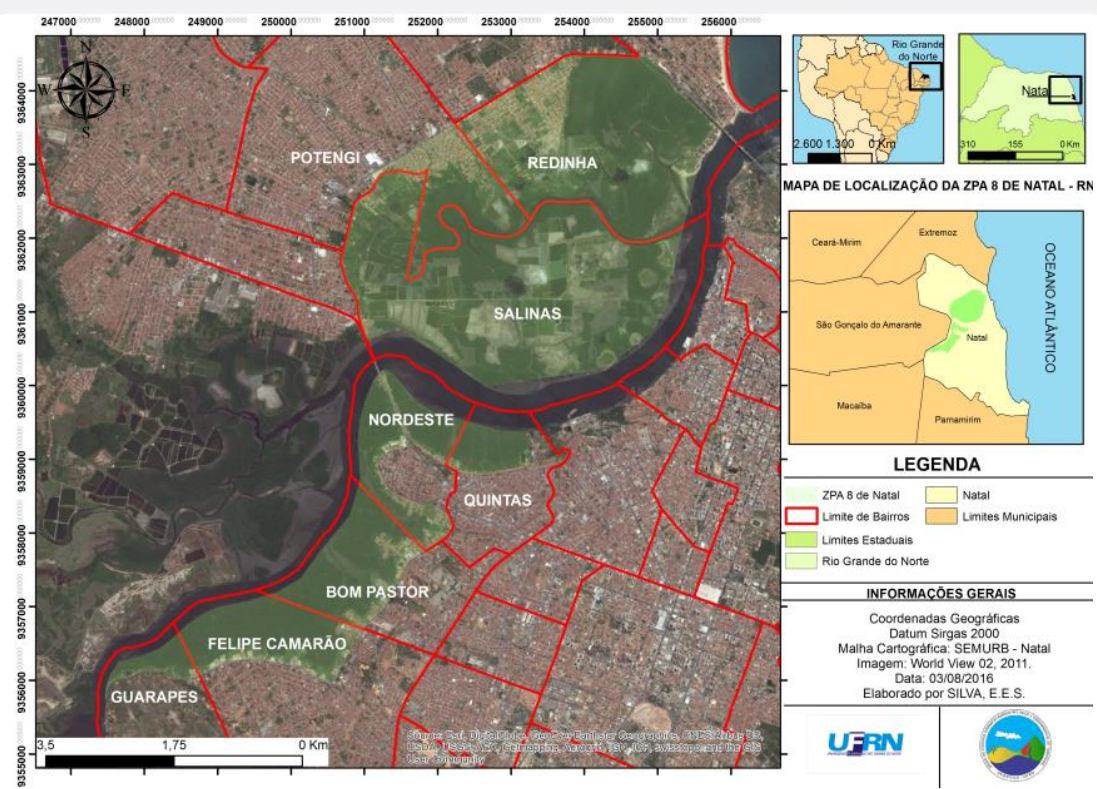

Figura 1: Floresta de mangue visualizada a partir do estuário. Fonte: acervo da autora, 2016.

No que diz respeito às suas dimensões, a ZPA 8 possui maior superfície, quando comparada as outras nove existentes no município; sua área se estende por aproximadamente 2.209,70 ha, o que totaliza cerca de 35,61\% do total da superfície das ZPAs e 13,11\%, quando relacionada à superfície total do município. No que diz respeito à identificação dos impactos ambientais, esta foi realizada a partir da visualização em campo, em visita técnica realizada em agosto/2016, levando em consideração que estes, geralmente, estão associados a desastres que causam danos à natureza, tais como mortandade de peixes em um rio, a eutrofização de uma lagoa, causando a perda de oxigênio desta, vazamento de petróleo em alto mar, queimadas, entre outros exemplos (SÁNCHEZ, 2006). O mesmo procedimento foi utilizado na identificação dos serviços ecossistêmicos, tomando como base a literatura específica sobre o tema, a qual foi amplamente consultada (MEA, 2005; GUPTA; NAIR (2012); MMA, (2011); FERREIRA, (2015); ANDRADE; ROMEIRO (2009); DE GROOT et al. (2002) COSTANZA et al. (1997).

\section{Resultados}

A partir da leitura das bibliografias referentes aos serviços ecossistêmicos e aos impactos ambientais, foi possível elencá-los, levando em consideração o trabalho de campo realizado no dia 27 de agosto de 2016, nos bairros Salinas e Potengi, onde foi possível visualizar os fenômenos e a sua intensidade, dentro da ZPA. Na mesma data, realizou-se uma aula passeio no barco Escola Chama-Maré, ao longo do estuário do Rio Potengi, sendo possível observar a dimensão da ZPA, bem como obter registros fotográficos do local. De posse dos dados, estes foram organizados no quadro a seguir: 
Tabela I: Impactos ambientais e serviços prejudicados pela ação destes.

\begin{tabular}{l} 
IMPACTOS IDENTIFICADOS \\
\hline - Supressão vegetal do mangue. \\
-Contaminação da água por resíduos químicos. \\
- Redução do estoque pesqueiro. \\
- Redução da área de manguezal. \\
- Contaminação das águas por efluentes das etapas \\
de engorda e despesca do camarão.
\end{tabular}

- Contaminação das águas e sedimentos do manguezal por esgoto bruto e por águas servidas advindas das ocupações.

-Contaminação do solo pelos dejetos suínos.

-Descarte inadequado de lixo no manguezal.

\section{SERVIÇOS PREJUDICADOS}

\section{PROVISÃO}

-Redução do estoque pesqueiro, de mariscos e crustáceos.

\section{REGULAÇAO}

- Gases do efeito estufa (CO2), hídrica, controle de erosão e retenção de sedimentos.

- Remoção de $\mathrm{CO} 2$ da atmosfera.

- Estabilidade geotécnica (prevenção de desastres naturais).

- Ciclagem de nutrientes - Controle de erosão

\section{SUPORTE}

- Formação do solo (gleissolo tiomórfico).

- Conectividade da paisagem.

- Manutenção da biodiversidade.

\section{CULTURAL}

- Contemplação

- Valores educacionais

- Valores históricos

- Beleza cênica

- Conservação da paisagem.

Fonte: elaborado pela autora.

\section{Discussões}

Ao elencar os impactos ambientais e os serviços ecossistêmicos prestados pelo manguezal, percebeu-se que a ZPA 8 de Natal é utilizada de modos diferenciados, pela população. Verificou-se a intensa atividade de carcinicultura no local, a qual é responsável por inviabilizar importantes serviços como a provisão de peixes e água. Durante a análise dos trabalhos estudados durante a pesquisa bibliográfica realizada, notouse que no âmbito nacional, poucas são as pesquisas relacionadas à temática dos serviços ecossistêmicos.

No tocante aos impactos ambientais, com base nos estudos de Sánchez (2006), consideram-se os resultados atribuídos plausíveis de relação com os serviços ecossistêmicos, e que os serviços de regulação e culturais são os mais possuem prejudicados a partir dos impactos identificados. Acredita-se que isso acontece devido aos serviços de regulação serem importantes para a manutenção de diversos tipos de vida, além dos processos naturais do ecossistema. 


\section{Conclusão}

A partir da pesquisa realizada para o presente estudo, foi possível compreender o conceito de serviços ecossistêmicos e impactos ambientais, de forma tal a aplicar estes conceitos em uma área de estudos possibilitando assim, apreendê-los na prática. Observou-se que existem diversas abordagens para tratar dos serviços ecossistêmicos, sendo possível escolher a que mais se adéqua aos objetivos da pesquisa em questão. Como discutido no trabalho, as Zonas de Proteção Ambiental configuram-se como importantes áreas para a conservação dos ecossistemas existentes no município de Natal. Apesar de esta categoria de unidade de conservação não estar incluída nas categorias estabelecidas pelo SNUC, as ZPA's já regulamentadas possuem legislação própria, as quais se baseiam nos critérios de criação de Unidades de Conservação. Foi possível concluir que a influência direta das atividades antrópicas resulta em impactos negativos para o ecossistema de manguezal e estuário da ZPA. Para um melhor entendimento qualitativo e quantitativo dos impactos ambientais negativos, futuramente, poder-se-á realizar uma avaliação de impactos ambientais, o que possibilitará propor medidas mais robustas para sanar tais problemas. Uma das principais alternativas a serem adotadas para a conservação do ecossistema é a efetivação da regulamentação proposta para a ZPA, bem como a criação permanente do Parque Estadual dos Mangues, a qual beneficiará principalmente o ecossistema presente no estuário. Em suma, espera-se que esta pesquisa possa evoluir, contribuindo para a gestão costeira do município de Natal - RN, no que diz respeito à relevante importância dos serviços ecossistêmicos do manguezal, para a sociedade natalense.

\section{Bibliografia}

ANDRADE, D. C.; ROMERO, A. R.. Serviços ecossistêmicos e sua importância para o sistema econômico e o bem-estar humano. IE/UNICAMP, n. 155, fev, 2009.

COSTANZA, R. Ecosystem services: multiple classification systems are needed. Biological Conservation, v. 141, p. 350-352, 2008.

DE GROOT, R. S., WILSON, A. M., \& BOUMANS, R. M. A typology for the classification, description and valuation of ecosystem functions, goods and services. Ecological Economics, v. 41, p. 393-408, 2002.

FERREIRA, J.C.V. et. al., Serviços Ambientais oferecidos pelas praias de Ponta Negra e Via Costeira: Perpectivas de Valoração . Revista do CERES. Caicó, RN: UFRN, 2015. 5p.

GUPTA, A.K.; NAIR, S.S.. Understanding Eco-DRR: Introduction to the Book. Ecosystem Approach to Disaster Risk Reduction, National Institute of Disaster Management, New Delhi, Pages 1-4 of 202. 
MEA - Millennium Ecosystem Assessment. Ecosystems and human well-being: synthesis. Washington: Island Press, 2005.

MMA - Ministério do Meio Ambiente. Pagamentos por Serviços Ambientais na Mata Atlântica: lições aprendidas e desafios. Brasília: MMA, 2011.

NATAL. Plano Diretor de Natal. Lei Comlementar $\mathrm{n}^{\circ}$ 07, de 05 de agosto de 1994. Disponível em: <http://medeirosadvogados.com/download/municipal/plano_diretor.pdf>

Plano Diretor de Natal. Lei $n^{\circ} 4.664$, de 31 de julho de 1995. Disponível em: <http://medeirosadvogados.com/download/municipal/plano_diretor.pdf>

Plano Diretor de Natal. Lei Complementar n 082, de 21 de junho de 2007. Disponível em:

<http://www.natal.rn.gov.br/_anexos/publicacao/dom/dom_20070623_especial.pdf>

SANCHEZ, L. H. Avaliação de impacto ambiental: conceitos e métodos. São Paulo: Oficina de texto, 2006, 495p.

SCHAEFFER-NOVELLI, Y.Manguezal ecossistema entre a terra e o mar.São Paulo: Caribbean Ecological Research, 1995, p. 7). 